\title{
A systematic review of factors affecting energy intake of adolescent girls.
}

\author{
Bibi Mushirah Jodhun, Dhandevi Pem, Rajesh Jeewon
}

Department of Health Sciences, Faculty of Science, University of Mauritius, Réduit, Mauritius

\begin{abstract}
Background: Adolescence is considered a critical period marked by an increase in energy intake to meet the body's physiological needs especially during puberty. This study reviews existing literature and critically analyses factors associated with eating habits and energy intake of adolescent girls.

Methods: A comprehensive search was conducted to identify at least 200 peer reviewed articles which dealt with the factors affecting energy intake (EI) and eating habits of adolescent girls. Studies were identified using a reference period between 1994 and 2016, based primarily on the PubMed/ CINL/ Science Direct/Google Scholar databases using keywords adolescent/ teenagers, factors/determinants and energy intake.

Results: No studies investigated all factors affecting energy intake among adolescents. Some studies found mixed association among the determinants of EI in adolescent girls. However, a number of reviews confirm that many factors namely physical activity level, socio-economic status, diet, individual and social factors do contribute to either a higher or a lower EI of adolescents. Conclusion: There is a dire need to consider factors associated with EI when designing nutritional intervention programs to prevent health problems in adulthood. The goal is not to change behavior of all but to increase the percentage of people adopting healthier lifestyle.
\end{abstract}

Keywords: Adolescent girls, energy intake, physical activity level, socio-economic status, nutrition education.

DOI: http://dx.doi.org/10.4314/ahs.v16i4.5

Cite as: Jodhun BM, Pem D, Jeewon R. A systematic review of factors affecting energy intake of adolescent girls. Afri Health Sci 2016;16(4): 910-922. bttp://dx.doi.org/10.4314/abs.v16it.5

\section{Background}

Adolescence represents one of the critical transitions in the life span and is characterized by rapid physical growth and changes in body composition, physiology, and endocrine with profound biological, emotional, social, and cognitive changes ${ }^{1}$. During adolescence nutritional and energy needs are increased due to the increased growth rate and changes in body composition associated with puberty $^{2}$. One point to be noted is that when energy intake (EI) exceeds energy expenditure, a state of positive energy balance occurs, resulting in weight gain ${ }^{3}$. Conversely, when energy expenditure exceeds EI, a state of
Corresponding author:
Rajesh Jeewon, Dept. Of Health Sciences,
Faculty of Science, University of Mauritius,
Réduit, Mauritius
Email: r.jeewon@uom.ac.mu

negative energy balance ensues, and the consequence is weight loss ${ }^{4}$. Therefore, considering how nutritional related health problems have risen drastically due to failure to consume a balanced diet, it seems critical to understand the food preferences and their relationships to BMI in adolescents especially in girls. This review provides an insight into the different factors affecting energy intake of adolescent girls.

\section{Methods}

Several inclusion criteria were used to warrant that all pertinent studies were reviewed. Studies were included if they met the following: (a) subjects were teenagers; (b) published between 1994 and 2016; (c) measured overall energy intake as a dependent variable; (d) evaluated predictors, factors, and determinants of energy intake; (e) research reported in English. Published and unpublished studies were counted in this review. A systematic review of the literature was undertaken using a reference period between 1994 and 2016, based primarily on the PubMed/ CINAHL/Science Direct/Google Scholar databases us- 
ing the key words adolescent/youth/teenage, factors/ determinants/predictors/correlates, and energy intake, eating habits. Computerized searches were directed on all the authors of the 220 studies that met the criteria. The titles and abstracts of the studies were screened for potential correlates of energy intake. From the initial search for peer-reviewed articles based on title and abstract, 138 full papers were read to assess if they should be considered further. Twenty-two studies were excluded because energy intake as well as eating habits were not a dependent variable. A total of 116 articles were considered appropriate for this review (Figure 1)

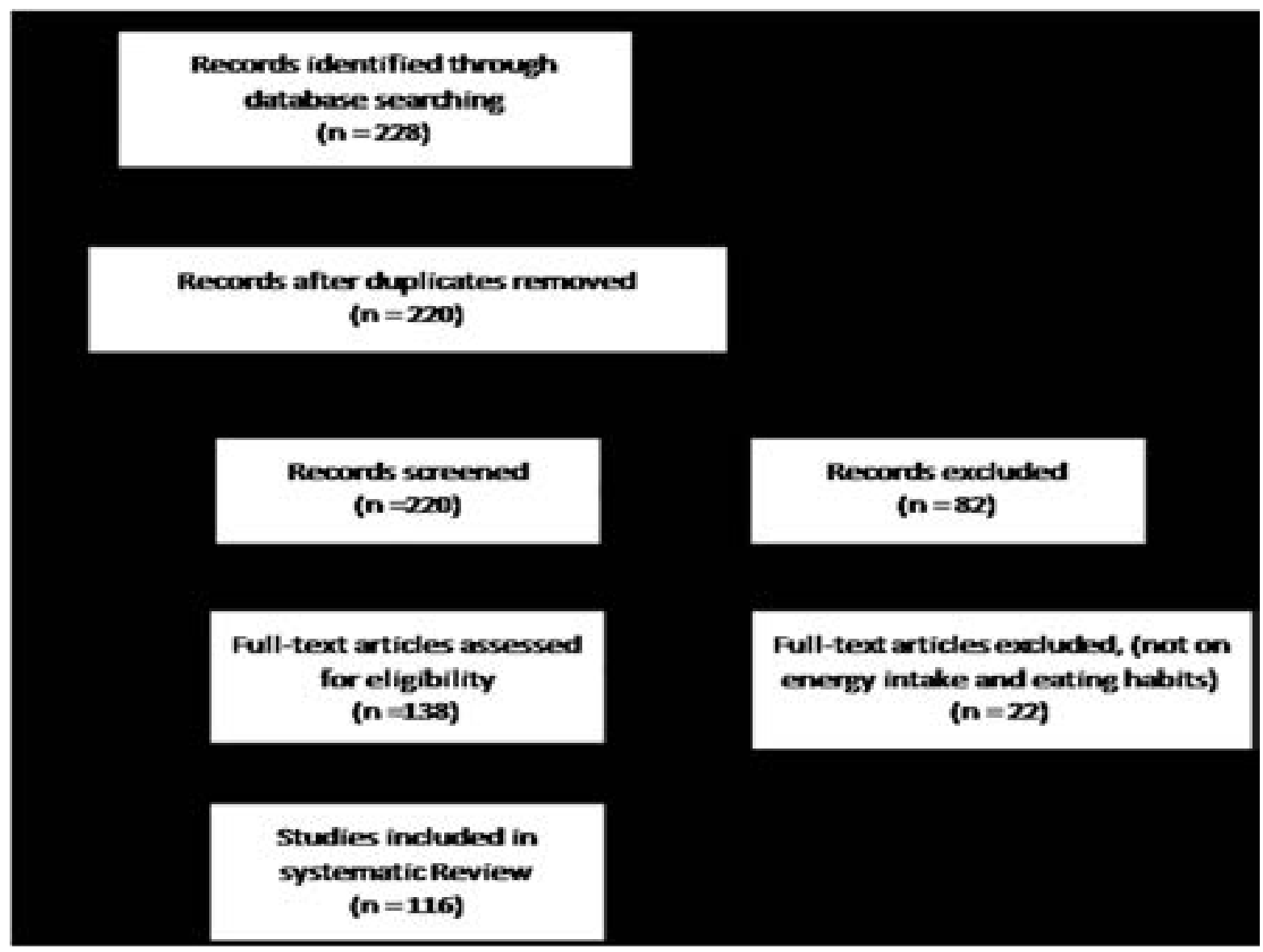

Results and discussion

Factors affecting energy intake \& eating habits of adolescent girls

It is well documented that EI is positively correlated with eating habits ${ }^{5}$ For instance, Llaurado et al. ${ }^{6}$ found that as the number of eating occasions increased in adolescents, so did the overall EI. However, it is worth pointing out that there are a number of important factors that do contribute to either a higher or a lower EI (Figure 2). 

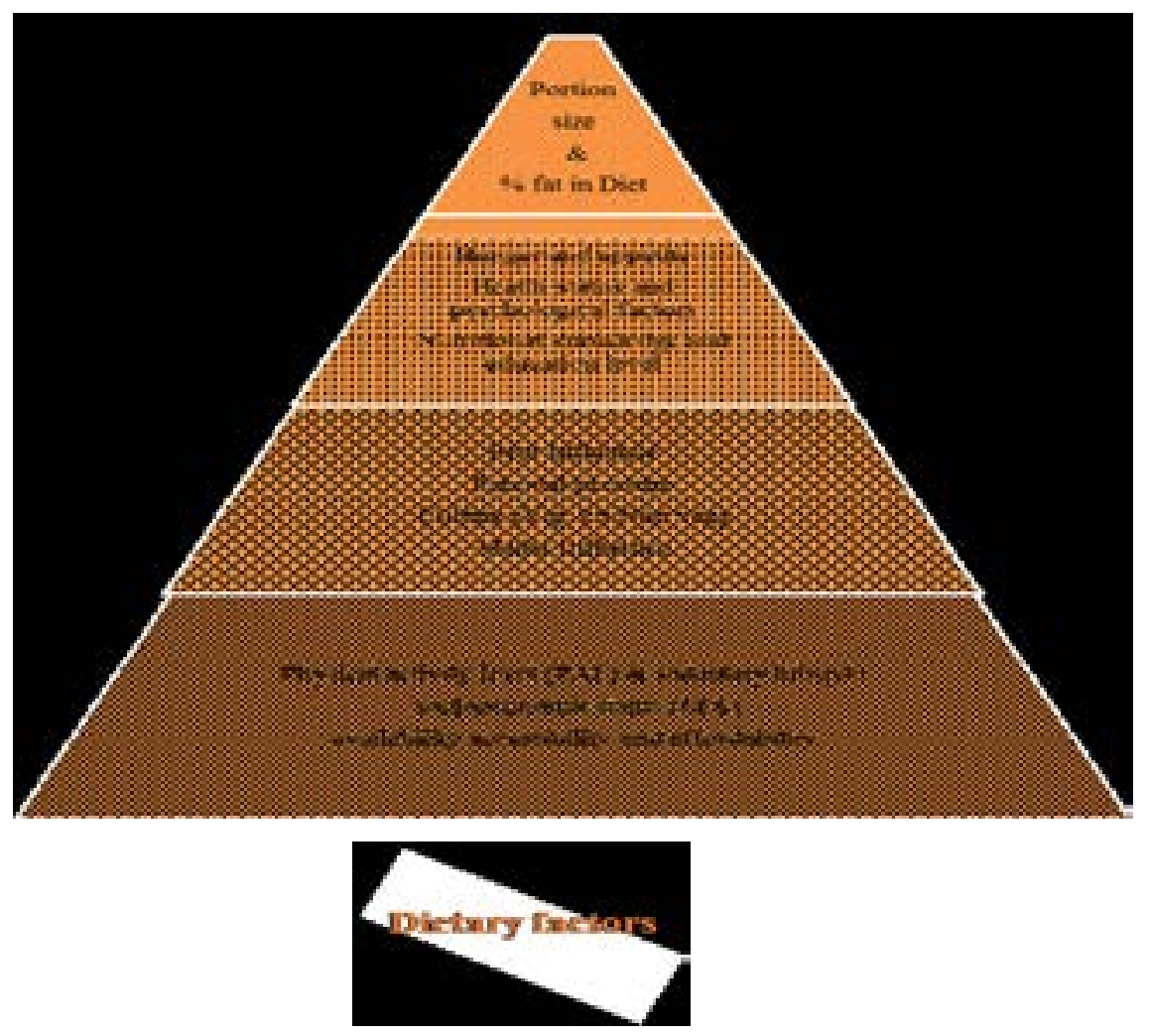

Figure 2 : Factors affecting energy intake

\section{Personal factors}

\section{Hunger, appetite and satiety}

Hunger is the physiological drive to find and eat food while appetite is the psychological desire to eat ${ }^{7}$. Satiety can be described as the state after a meal during which hunger is dampened and the urge to consume food is inhibited ${ }^{8}$. Weigle et al. ${ }^{9}$ reported that an isocaloric high-protein diet markedly increased satiety while slow eating has been shown to decrease hunger and promote greater satiety ${ }^{10}$. Many studies have demonstrated that slow eating helps control EI since it enhances satiety ${ }^{11}$. Consequently, decreased hunger and increased satiety will eventually discourage more food consumption, hence lower EI. However, the mechanisms responsible for regulation of appetite and food intake still warrants further investigation ${ }^{12}$.

\section{Health status and body image}

Nowadays it is the desire of most girls to be thin keeping in mind the ideal female body image. This attitude is driven, to a large extent by movie and television celebrities, fashion models and beauty pageant contestants whereby society considers thin to be healthy ${ }^{13}$. BMI is positively associated with concern about weight and shape and frequency of dieting and the latter was more prevalent among obese pre-adolescent and adolescent girls ${ }^{14}$.

Similarly, Japanese females with low BMI had high body dissatisfaction ${ }^{15}$. Moreover, Howe et al. ${ }^{16}$ reported a significant negative association between frequency of dieting and EI among high school students. However, Sharma et al. ${ }^{17}$ argued that body dissatisfaction was significantly associated with total energy intake with an increased intake of all macronutrients. Body image distortion and overall body dissatisfaction among adolescents may eventually lead to disordered eating behaviours such as anorexia nervosa or bulimia ${ }^{18}$. Raymond et al. ${ }^{19}$ observed that females who had binge eating disorders consumed significantly more kilocalories and more macronutrients while anorectic restrictors consumed significantly more energy to gain weight than did the anorectic bulimics (a mean of 3055 kcals per day vs. a mean of 2788 kcal per day) ${ }^{20}$. Contrarily, according to Higgins et al. ${ }^{21}$ patients with anorexia nervosa had a mean daily energy intake of 1272 kcal which was significantly lower than the mean EI for normal individuals. 


\section{Educational level and nutrition knowledge}

Despite the fact that many young adults have inadequate knowledge about good nutrition, including information on recommended servings of specific food groups, only one in five $(21.6 \%)$ university students felt a lack of nutritional knowledge (NK) was an actual barrier to healthy eating $^{22}$. Most adolescents are fully aware of the type of food that they should consume. To support this, some studies have shown that some adolescents, despite having a significant amount of knowledge regarding healthy foods, find it difficult to follow healthy eating guidelines and frequently consume foods that they perceive as unhealthy ${ }^{23,24}$. On the other hand, girls had higher knowledge scores than boys ${ }^{25}$, particularly because girls and older adolescents were more likely to read nutritional food labels ${ }^{26,27}$. Although education was not associated with the risk of being thin, Alam et al. ${ }^{3}$ reported that Bangladeshi girls with lower education were more likely to be stunted than girls with higher education. Despite the fact that many adolescent girls are not aware about their nutritional requirements ${ }^{28}$, knowledge of girls about the need for extra nutrients in adolescence did not have an effect on the prevalence of stunting ${ }^{29}$. However private school girls had significantly better knowledge than governmental school girls as regards to healthy food, low fat cheese, best food to eat during dieting ${ }^{28}$. As a matter of fact, O'Brien and Davies ${ }^{30}$, Shabaan et al. ${ }^{31}$ and Wolfgang et al. ${ }^{32}$ reported that there was no significant relationship between nutrition knowledge and BMI, nutrition behaviours or food preferences, suggesting that there may be reasons other than poor nutrition knowledge that account for the higher EI and BMI of respondents.

\section{Environmental factors}

\section{Physical activity level and sedentary lifestyle}

Physical activity (PA) plays a significant role in non-communicable diseases prevention and accounts for about $20-40 \%$ of total energy expenditure ${ }^{33}$. The working body requires energy and nutrients in order to fuel activity and function. PA, on the other hand, manipulates energy expenditure and regulates the use of fuels ${ }^{34}$. PA is closely interrelated with $\mathrm{EI}^{35}$ and has been shown to decline during adolescence especially among the American, Canadian and Finnish youth ${ }^{36}$. Increasing westernisation, urbanisation and mechanisation occurring in most countries around the world are associated with changes in the diet towards one of high fat, high energy-dense foods and a sedentary lifestyle ${ }^{37}$. Prolonged strenuous PA per- formed on a regular basis causes an increase in overall energy turnover, and leads either to loss of body weight, or to an increased food intake ${ }^{34}$. To support this statement, Zalilah et al..$^{38}$, Fulton et al. ${ }^{35}$ and Goyal et al..$^{39}$ reported that physical activity was inversely related to increases in BMI, overweight, obesity and adiposity whereby overweight children had reduced physical fitness due to increased physical inactivity. As energy output is increased through exercise, an individual must increase energy intake to match expenditure in order to maintain body mass. In highly physically trained persons, daily energy expenditure due to vigorous exercise is generally matched by a high-energy intake ${ }^{40}$. Obese adolescents engaged in sports less often than normal-weight and overweight participants, but underweight adolescents reported the least amount of time devoted to sports ${ }^{41}$. Interestingly Fokeena and Jeewon ${ }^{42}$ found that high PA was more common among the high SES adolescents as compared to the low SES. This can be due to the unsafe environments of the low SES neighborhoods and less access to recreational resources compared to high SES areas ${ }^{43}$. A decrease in spontaneous daily energy consumption and a reduction in energy balance were observed in obese adolescents with high intensity exercise whereas low intensity exercise had no effect on energy intake ${ }^{44}$.

Several studies have investigated the association between eating habits and (Physical activity levels)AL. Ottavaere et al. $^{45}$ found that male and female adolescents with the highest physical activity levels, consumed more fruit and milk products and less cheese compared to the least active adolescents and that the energy intake was higher among those who participated more frequently in sport activities. Nowadays with advances in technology young teens spend more time in sedentary activities such as watching television, reading, eating, chatting with friends or playing video games than indulging in physical activities ${ }^{46}$. Fear of violence, secondary to drug dealing, and fear of kidnapping provide parents with no other alternatives than to keep children in the house and avoid outside sports and activities ${ }^{47}$. However physical activity and sedentary behavior are not always associated with children's overweight and/or obesity ${ }^{48}$ and one plausible explanation is that PA may not be a risk factor of obesity during adolescence ${ }^{49}$.

\section{Socioeconomic status (SES)}

Socioeconomic status (SES) is postulated to be a major 
predictor of dietary intake and lifestyle which are the major contributors to weight problems ${ }^{42}$. In a study among Lebanese adolescents, energy and nutrient intake analysis showed that adolescents in the high-SES group consumed significantly higher amounts of calories, protein, fat and significantly lower amounts of carbohydrates ${ }^{50}$. The relationship between SES and energy intake is complex. In developing countries, results are otherwise. The prevalence of stunting in urban Cameroon (Africa) was two times higher among the urban adolescents with low SES $(12 \%)$ compared to those from high SES $(5 \%)^{51}$. Urban adolescents with high SES and girls reported a more frequent consumption of in-between meals and most food groups compared to the rural adolescents. Lower education and lower socio-economically family background is associated with less healthy dietary patterns ${ }^{52}$. Children and young people from a lower socioeconomic background and those whose mothers had a lower level of education consume more sweets and high-fat bakery products as well as sugary and salted snacks, but lower vegetables intake ${ }^{53}$.

Contrarily Goyal et al. ${ }^{54}$ reported that the prevalence of overweight among children was higher in middle SES as compared to higher SES group while prevalence of obesity was higher in high SES group as compared to middle SES group. Additionally, Manios et al.$^{55}$ reported that middle/ high SES children had higher energy intake compared to their low SES counterparts. This can be because high class people have better access to energy-dense and expensive foods such as meat than the poor ${ }^{54}$. Moreover Darmon et al. ${ }^{56}$ reported that adolescents with high SES had significantly higher percentage of energy intake from fat while the low SES had higher percentage of energy intake from carbohydrate. In contrast, Fokeena and Jeewon $^{42}$ reported that among Mauritian adolescents, consumption of vegetables, low fat protein sources, and sweetened and fatty foods were higher in the low SES group while the high SES group consumed more fruits, wholegrain cereals, refined cereals, milk and dairy products whether low fat or full-cream, and high fat protein sources along with fast foods. While high income people can afford healthy food products, adolescents with low SES do not always eat properly because of poverty ${ }^{57}$. It has also been reported that female adolescents from larger families and males from families with higher incomes were less likely to be overweight and consumed less calories than their low SES peers ${ }^{58}$.

African Health Sciences Vol 16 Issue 4, December, 2016

\section{Availability and accessibility}

During adolescence, teens spend less time with family and more time with friends. As teens become more independent, eating away from home increases ${ }^{59}$. The mushrooming of shopping malls, convenience stores, vending machines, delivery options, restaurants and fast food outlets encourage adolescents to practice unhealthy eating habits ${ }^{60}$. The average teen eats at a fast food restaurant at least twice a week. Fast food visits account for 31\% of all food eaten away from home, and make up 83\% of adolescent visits to restaurants ${ }^{59}$. This has eventually resulted an obesogenic environment whereby traditional foods face greater competition than before and high energy dense foods are made easily available for teenagers $^{61}$. These food items, super-sized fast food meals, soft drinks, bags of chips, king- sized candy bars and oversized pizzas have contributed to excessive caloric sugar, high in glycemic load and fat intake among adolescents resulting in excess daily energy requirements ${ }^{62}$. Female adolescents who reported eating at a fast food restaurant $\geq 3$ times in the past week had energy intake 37\% more than those who did not eat at a fast food outlet ${ }^{63}$. Moreover mean energy intake from fast food meal among adolescents was extremely large $(1652 \mathrm{kcal})$, accounting for $61.6 \%$ of estimated daily energy requirements ${ }^{64}$.

\section{Social factor \\ Media}

The mass media, mainly the television have become a powerful force throughout the world and strongly influence the behaviours of people ${ }^{65}$. Australian children are exposed to more television food advertising than probably children of every other nationality ${ }^{66}$. These long hours of television viewing are positively associated with overweight and obesity among girls ${ }^{65,67}$. These contribute to excess energy intake both by decreasing the amount of physical activity hence reducing energy expenditure and from increased unhealthy snacking during television viewing or as a result of exposure to food advertising ${ }^{68}$. High television/video use among boys and girls is associated with more unhealthful dietary behaviours (eg increased consumption of soft drinks, fried foods, and snacks). In contrast, time spent reading/doing homework was associated with more healthful dietary behaviours (such as increased consumption of fruits and vegetables) ${ }^{69}$. Moreover, fast food restaurants and energy-dense 
foods and drinks are among the most advertised products on television ${ }^{63}$ and children are often the targeted market. The fat, sugar and energy content of foods advertised to children are very high compared to their daily needs ${ }^{70}$. $\mathrm{Chou}^{68}$ found a strong positive correlation between exposure to fast food restaurant advertising and the probability that children and adolescents are overweight especially among girls. However, such is not always true. According to Amos et al. ${ }^{65}$, media influences did not significantly correlate with students' eating habits. External factors such as values pertaining to food, socioeconomic status, family, and availability of food that have an impact on eating habits might have been the real predictors ${ }^{71}$. Interestingly female teens who are more concerned of their weight and figure, indulge in slimming diets and are more willing to choose low-fat foods such as fruits and vegetables $^{72}$. Advertising healthy and nutritious foods to children encourage positive attitudes and beliefs towards the food and may increase children's willingness to choose healthy food as a snack ${ }^{73}$.

\section{Influence of parents and friends}

Studies have shown that parents and peers do have a strong influence on youths' eating habits especially on weight control behaviours of female adolescents ${ }^{74}$. Parental body weight is often described as a predictor of obesity in children, both in their childhood and adulthood, either to the genetic characteristics and/or attitudes and behaviours of parents with their children ${ }^{75}$. Brown and Odgen ${ }^{76}$ reported significant correlations between parent and child for reported snack intake, eating motivations and body dissatisfaction and therefore indicates an important role for modelling. Salvy et al. ${ }^{74}$ observed that female adolescents consumed more healthy foods and fewer unhealthy snacks when they were with their friends than when with their mothers which lead to the fact that parents may act as an inhibitory influence on healthy eating. In contrast, there has been opposing views on same whereby adolescents, out of home, consume healthy foods with family but more 'junk type of food' with peers ${ }^{77}$. Additionally, it has been reported that parents with longer working hours might have less time and energy to spend on preparation of healthy meals or exercise with their children ${ }^{78}$. However, Wang et al. ${ }^{79}$ concluded that there was a weak relationship between parental and child dietary patterns in the target urban low-income African-American population group in the United States while Scaglioni et al. ${ }^{80}$ found no relationship between parents' and child eating habits. Adolescents often compare themselves to their friends and may alter their choices to conform to the behaviour of their peers ${ }^{81}$. Amos et al. ${ }^{65}$ concluded that there was a significant positive relationship between peer influence and eating habits suggesting that the higher the peer pressure, the more unhealthy the students' dietary intake. All evidence suggests that the presence of peers and friends increases children and adolescents' energy intake ${ }^{74}$.

\section{Culture (Veg vs Non-Veg diet)}

Culture and religion is one of a broad range of factors that has an effect on the eating habits of adolescents ${ }^{82}$. Different ethnic groups demonstrate marked differences in the character and amounts of foods eaten ${ }^{47}$. People in the United States and other developed countries are becoming more affluent and able to afford more food especially processed and ready-to-eat foods, which tend to have a higher energy density while the median Indian household consumes far fewer calories than the recommended caloric intake ${ }^{83}$. Cultural food preferences vary most dramatically across India particularly vegetarianism because of the attitude towards animal products ${ }^{84}$.

Adolescents adopt vegetarian eating plans for a variety of reasons, including cultural or religious beliefs, moral or environmental concerns, health beliefs, as a means to restrict calories and/or fat intake and as a means of exerting independence by adopting eating behaviors that differ from those of the teen's family ${ }^{59}$. Restricted vegetarians are more likely to be females from a higher SES group and have healthier eating attitudes than the semi-vegetari$\mathrm{an}^{85}$. Vegetarian adolescents have been found to be shorter and leaner than omnivores during childhood and experience a delay in puberty and menarche at a later age than among non-vegetarians ${ }^{86}$. After puberty, vegetarian adolescents are as tall or taller than omnivores and are generally leaner, although final adult height may be reached at a later age ${ }^{87}$. Perry ${ }^{88}$ stated that vegetarian adolescents are twice as likely to consume fruits and vegetables, one-third as likely to consume sweets, and one-fourth as likely to consume salty snack foods once per day. This is supported by $\mathrm{O}^{\prime} \mathrm{Brien}^{89}$ who reported that current vegetarians in the younger and older cohorts had healthier dietary intakes than non- vegetarians with regard to fruits, vegetables, and fat. However adolescent vegetarians, especially adolescent males, have been found to be at high 
risk for engaging in unhealthy and often extreme weight loss behaviours ${ }^{90}$. This observation is corroborated with those who found that energy intakes of the vegetarian adolescents were well below the reference values $(66 \%)^{91}$. Children who follow certain vegetarian diets, particularly vegan diets, are reported to have difficulty acquiring adequate energy intake ${ }^{92}$. Protein intake was higher in omnivores than in lacto-ovo-vegetarians but was still adequate for their weight ${ }^{93}$. However, Sanders and Reddy ${ }^{94}$ and Donovan and Gibson ${ }^{95}$ argued that total energy intakes were similar to those reported in non-vegetarian children. Lamisse $^{96}$ also concluded that energy intake of lacto-ovo vegetarians was not significantly different from that of the omnivores, though slightly lower.

\section{Dietary factors}

\section{Portion size and percentage of fat in the diet}

The current obesogenic eating environment is characterized by convenient, relatively inexpensive, energy dense and highly palatable foods served in large portions. An increase in portion size of foods in recent years have resulted in an "obesogenic" environmental influence for children by producing excessive intake at meals ${ }^{97,98}$. Though it is not clear why children are more influenced by portion size as they age, Ello-Martin et al. ${ }^{99}$ reported that portion size influences the development of hunger and satiety with higher levels of overeating. Thus, when offered bigger portions, subjects ate a larger amount before they reached satiation ${ }^{100}$. To support this statement, a significant relationship between the amount of food provided and energy intake was observed whereby subjects consumed 30\% more energy (676 kJ) when offered the largest portion than when offered the smallest portion ${ }^{101}$. The combined effects of high-energy density and large portion size may also lead to excess energy intakes and body weight gain ${ }^{102}$. On the other hand, smaller bite sizes or pauses within meals have been associated with reduced energy intake in some studies ${ }^{98}$, or conversely have led to no differences in overall energy intake ${ }^{103}$. The latter reported that energy intake during a fast food meal was not influenced by portion sizes. Therefore, it can be argued that other inherent characteristics such as the nutritional composition, palatability, high fat content of conventional fast food are more likely to promote excess energy intake. In general foods that are high in fat tend to be energy dense, highly palatable and promote overconsumption, hence leading to excess energy intake and eventually weight gain ${ }^{104}$. Astrup et al. ${ }^{105}$ argued that reduced fat diets consistently results in a reduced total energy intake and reduced weight gain. Fats also carry many aromatic compounds that add flavour to foods and, therefore, high fat foods may be overconsumed. Adolescents tend to exceed the recommendation for fat intake $(32 \% \text { to } 40 \%)^{106}$. Swedish and Norwegian children and adolescents have the lowest fat intake in Europe (30-33\%), whereas Spain, Greece and UK have the highest $(>40 \%)^{107}$. This trend persists in developing countries whereby percentage of fat was $25.6 \mathrm{~g} /$ day for Tanzanian adolescent girls ${ }^{108}$ while in India the majority had percentage fat intake well below the $\mathrm{RDA}^{28}$.

\section{Snacking and meal skipping}

Adolescents develop their own values, including values relating to food and meals ${ }^{109}$. The eating pattern of adolescents has changed rapidly towards the trend of increased snacking and high-fat food intake, and greater frequency of eating outside the home or meal skipping ${ }^{110}$. Adolescent girls are more likely to skip breakfast than adolescent boys ${ }^{111}$. Shils et al. ${ }^{2}$ reported that approximately $20 \%$ of adolescents skip breakfast each day. Breakfast calories have the greatest influence on daily energy intake and skipping breakfast is associated with lower total daily intake ${ }^{112}$. Moreover, girls with irregular breakfast and lunch intake had higher percent of energy from in-between meals (19\% from 'snack food') and less healthy food choice including lower intake of milk, vegetables, brown bread. They also consume more soft drinks and sweets compared to girls with regular meal pattern ${ }^{113}$. Snacks contribute $30 \%$ increase in the amount of daily energy, $612 \mathrm{Kcal} /$ day in ${ }^{114}$. In 2005-2006, higher snacking frequency was associated with higher total calorie intake ${ }^{115}$. Adolescents who had 4 or more snacks in a day consumed over 1.5 times as many calories as did adolescents who reported no snacks ${ }^{116}$. Sonoo et al. ${ }^{24}$ reported that snacking was highly prevalent $(84 \%)$ and occurred more often in female teens, urban residents and middle and higher income groups while Bargiota et al. ${ }^{27}$ observed that about half of the adolescents purchased a snack daily from the school canteen and half of them had an afternoon snack out with peers.

\section{Study limitations}

Most of the studies assessed relied on self-reported data and cross-sectional study designs with descriptive statistics. There were difficulties to compare findings of reviewed studies due to differences in study designs, meth- 
ods of data collection and characteristics of samples participants. To obtain more comprehensive information on the predictive determinants affecting energy intake, more longitudinal studies are needed. In addition, future research should possibly adopt measurement approaches that use both self-report and objective measurements to measure predictive factors and determinants of energy intake more accurately. Some studies used theoretical framework which are important to identify behavior change and enabling development of effective interventions among youth. Most of the research studies did not assess the effects among the variables or the direction of their effects. Assessing determinants of eating habits and energy intake objectively is a topic of recent interest ${ }^{117}$. Limited studies on determinants of environmental factors on snacking which are linked to energy intake were found and this may be because the role of physical environment is of recent interest ${ }^{118}$.

\section{Conclusion}

The factors discussed in the present systematic review are namely physical activity level, socioeconomic status, diet ,individual and social factors which do have an impact on energy intake and eating habits. Obviously, there are other factors not discussed here such as the genetic factor, basal metabolic rate (BMR), and total energy expenditure (TEE) to name but a few. All the examples and studies in this study revealed clear patterns towards nutritional behaviours of adolescent girls. As evident in this review, there are mixed results regarding the impact of the different factors on subsequent energy intake. To conclude, it is a dire need to consider these factors when designing nutritional interventional programs so as to prevent shortterm health problems and chronic disease in adulthood. The goal is not to change behaviour of all but to increase the percentage of people adopting healthier lifestyle and eating habits.

\section{Ethical considerations}

Ethical issues (Including plagiarism, informed consent, misconduct, data fabrication and/or falsification, double publication and/orsubmission, redundancy, etc.) have been completely observed by the authors.

\section{Funding}

No Funding source is involved in this study.

\section{Acknowledgements}

The Department of Health Sciences, Faculty of Science, University of Mauritius is acknowledged for research support.

\section{Conflict of interest}

The authors declare none.

\section{References}

1. Alam N, Roy SK, Shamsir Ahmed, AM. (2010). Nutritional Status, Dietary Intake, and Relevant Knowledge of Adolescent Girls in Rural Bangladesh. J Health Popul Nutr, 28(1) 86-94.

2. Shills ME, Shirke M, Ross CA et al. (2006). Modern Nutrition in Health \& Disease. 10th ed. Baltimore: Lippincott Williams \& Wilkins.

3. O. Hill J, Wyatt HR, John C, Peter, S. (2012). Energy Balance and Obesity. Circulation, 126, 126-132.

4. Hall KD, Heymfield ST, Kemnitz JW, et al. (2012). Energy balance and its components: implications for body weight regulation. Am J Clin Nutr, 95, 989-994.

5. Kerver JM, Yang EJ, Obayashi S, et al. (2006). Meal and snack patterns are associated with dietary intake of energy and nutrients in US adults. J Am Diet Assoc, 106(1):4653.

6. Llaurado E, Albat SA, Giralt M et al. (2016). The effect of snacking and eating frequency on dietary quality in British adolescents. Eur J Nutr, 55(4): 1789-97.

7. Gibney MJ, Lanham-New SA, Cassidy A. et al. (2009). The Nutrition Society Textbook series. 2nd Ed, Introduction to Human Nutrition. United Kingdom, John Wiley \& Sons, Ltd.

8. Sturm K, Parker B, Wishart J, et al. (2004). Energy intake and appetite are related to antral area in healthy young and older subjects. Am J Clin Nutr, 80, 656-67.

9. Weigle DW, Breen PA, Matthys CC, et al. (2005). A high-protein diet induces sustained reductions in appetite, ad libitum caloric intake, and body weight despite compensatory changes in diurnal plasma leptin and ghrelin concentrations. Am J Clin Nutr, 82(1), 41-48

10. Andrade AM, Kresge DL, Teixeira PJ, et al.(2012). Does eating slowly influence appetite and energy intake when water intake is controlled? Int J Behav Nutr Phys Act, 9, 135.

11. Melanson KJ. (2004) Food intake regulation in body weight management: a primer. Nutr Today. 39(5):203-215. 12. Ozen VS, Sonmez TG, Bugdayci G, Ozen G. (2011). the effects of exercise on food intake and hunger: rela- 
tionship with acylated ghrelin and leptin. J Sports Sci Med, 10, 283-291.

13. Gropper SQ, Smith JL, Groff JL. (2009). Advanced Nutrition and Human Metabolism. 5th Edition. Wadsworth, Cengage Learning.

14. Haines J, Neumark-Sztainer D. (2006). Prevention of obesity and eating disorders: a consideration of shared risk factors. Health Educ Res, 21 (6): 770-782.

15. Chisuwa N, O’Dea JA. (2010). Body image and eating disorders amongst Japanese adolescents. A review of the literature. Appetite, 54, 5-15.

16. Howe AS, Black KE, Wong JE et al. (2013). Dieting status influences associations between dietary patterns and body composition in adolescents: a cross-sectional study. Nutr J, 12:51.

17. Sharmaa S, Ikedaa J, Fleming SE. (2013). Influence of body dissatisfaction on 1-year change in nutrient intake of overweight and obese inner-city African American children. Body Image, 10, 121-126.

18. Pike KM, Dunne PE. (2015). The rise of eating disorders in Asia: a review. Int J Eat Disord. 3:33.

19. Raymond NC, Neumeyer B, Warren CS. et al. (2003). Energy intake patterns in obese women with binge eating disorder. Obes Res, 11(7), 869-879.

20. Sunday SR, Halmi K A. (2003). Energy intake and body composition in anorexia and bulimia nervosa. Physiol. Behav, 78(1), 11-7.

21. Higgins J, Hagman J, Pan Z, MacLean P. (2013) Increased Physical Activity Not Decreased Energy Intake Is Associated with Inpatient Medical Treatment for Anorexia Nervosa in Adolescent Females. Kappen C, ed. Plos one, 8(4): e61559.

22. King KA, Mohl K, Bernard AL, Vidourek RA. (2007). Does involvement in healthy eating among university students differ based on exercise status and reasons for exercise? Californian J Health Promot, 5(3), 106-119.

23. Croll JK, Nuemark SD, Story M. (2001). Healthy eating: What does it mean to adolescents? J Nutr Educ, 33, 193-198.

24. Sonoo R, Mahomoodally FM, Ramasawmy D. (2013). Is Healthy Eating Behaviour Common among School Adolescents in Mauritius? Curr Res Nutr Food Sci J, 1(1), 11-22.

25. Kersting M, Sichert-Hellert W, Vereecken CA. et al. (2008). Food and nutrient intake, nutritional knowledge and diet-related attitudes in European adolescents. Int J Obes, 32, S35-S41.
26. Cannoosamy K, Jeewon R, Pugo-Gunsam P. (2014). A Study on Consumer's Knowledge and Attitudes towards Nutritional Labels. J Nutr Educ and Behav, 46 (5), 334-340.

27. Bargiota A, Delizona M, Tsitouras A, Koukoulis GN. (2013). Eating habits and factors affecting food choice of adolescents living in rural areas. Hormones, 12(2), 246253.

28. Choudhary S, Mishra CP, Shukla KP. (2010). Dietary pattern and Nutrition Related Knowledge of rural adolescent girls. Indian J Prev Soc Med. 41(3) (4).

29. Teji K, Dessie Y, Assebe T, Abdo M. (2016). Anaemia and nutritional status of adolescent girls in Babile District, Eastern Ethiopia. Pan Afr Med J; 24:62.

30. O'Brien GO, Davies M. (2007). Nutrition knowledge and body mass index. Health Educ Res, 22(4), 571-575.

31. Shaaban SY, Nassar MF, Abd Elhamid DM et al. (2009). Nutritional Knowledge and Attitude of Adolescent School Girls Living in Cairo. Int. J. Med. Med. Sci., 4(2): 421-427.

32. Wolfgang SH, Beghin L, De Henauw S et al. (2011). Nutritional knowledge in European adolescents: results from the HELENA (Healthy Lifestyle in Europe by Nutrition in Adolescence) study. Public Health Nutr, 14(12), 2083-2091.

33. World Health Organisation (2014). Global status report on noncommunicable diseases 2014. Available at:

h t t p : / / a p p s. wh o. in t / i r i s / b i t s t r e am/10665/148114/1/9789241564854_eng.pdf

34. Melzer K, Kayserb B, Sarisc WHM, Picharda C. (2005). Effects of physical activity on food intake. Clin Nutr, 24, 885-895.

35. Fulton JE, Dai S, Steffen LM et al. (2009). Physical Activity, Energy Intake, Sedentary Behaviour, and Adiposity in Youth. Am J Prev Med, 37(1S).

36. Allison KR, Adlaf EM, Dwyer JJM, Lysy DC, Irving HM. (2007). The Decline in Physical Activity among Adolescent Students. A Cross-national Comparison. Canadian J Public Health, 98(2).

37. Popkin BM (2001). The nutrition transition and obesity in the developing world. J Nutr, 131(3), 871S-3S.

38. Zalilah MS, Khor GL, Mirnalini K et al. (2006). Dietary intake, physical activity and energy expenditure of Malaysian adolescents. Singapore Med J, 47(6), 491.

39. Goyal RK, Shah VN, Saboo BD, et al. (2010). Prevalence of Overweight and Obesity in India. Adolescent School Going Children: Its Relationship with Socioeco- 
nomic Status and Associated Lifestyle Factors. $J$ Assoc Physicians India, 58.

40. Chaput J-P, Klingenberg L, Rosenkilde M, et al. (2011). Physical Activity Plays an Important Role in Body Weight Regulation. J Obes: 360257.

41. Elgara FJ, Robertsb C, Moorec L, Tudor-Smith C. (2005). Sedentary behaviour, physical activity and weight problems in adolescents in Wales. Public Health, 119, 518524.

42. Fokeena WB, Jeewon R. (2012). "Is There an Association between Socioeconomic Status and Body Mass Index among Adolescents in Mauritius?" Sci World J.

43. Moore LV, Roux AVD, Evenson KR et al (2008). "Availability of recreational resources in minority and low socioeconomic status areas." Am J Prev Med, 34(1), 16-22. 44. Thivel D, Isacco L, Montaurier C et al. (2012). The 24-h Energy Intake of Obese Adolescents Is Spontaneously Reduced after Intensive Exercise: A Randomized Controlled Trial in Calorimetric Chambers. Plos One, 7, 1. 45. Ottevaere C, Huybrechts I, Béghin L, et al. (2011). Relationship between self-reported dietary intake and physical activity levels among adolescents: The Helena study. Int J Behav Nutr Phys Act, 8:8.

46. Ogechi UP, Akhakhia OI, Ugwunna UA. (2007). Nutritional Status and Energy intake of adolescents in Umuahia Urban, Nigeria. PJN, 6(6), 641-646.

47. Goldstein SE, Davis-Kean PE, Eccles JS. (2005). Parents, peers, and problem behaviour: a longitudinal investigation of the impact of relationship perceptions and characteristics on the development of adolescent problem behaviour. Dev Psychol; 41(2):401-13.

48. Parkes A, Sweeting H, Wight D. (2012). Growing Up in Scotland: Overweight, obesity and activity, Edinburgh. Scottish Government. Available at: http://www.gov. scot/Resource/0039/00392688.pdf

49. Chou YC, Pei JS. (2010). Risk Factors of Adolescent Obesity in Taiwan and Its Association with Physical activity, Blood Pressure and Waist Circumference. Asian J Sports Med, 1(4), 214-222.

50. Nabhani ZM, Naja F, Nasreddine L. (2011). Dietary intake and nutrition-related knowledge in a sample of Lebanese adolescents of contrasting socioeconomic status. Food Nutr Bull, 32(2), 75-83.

51. Dapi LN. (2010). Socioeconomic and sex differences in adolescents' dietary intake, anthropometry andphysical activity in Cameroon Africa. Department of Public Health and Clinical Medicine Epidemiology and Global Health Umeå University.
52. Aranceta J, Perez-Rodrigo C, Ribas L, Serra-Majem, L (2003). Sociodemographic and lifestyle determinants of food patterns in Spanish children and adolescents: the enKid study. Eur J Clin. Nutr, 57(1), S40-S44.

53. Datar A, Nicosia N. (2012). Junk Food in Schools and Childhood Obesity. Journal of Policy Analysis and Management: J Policy Anal Manage, 31(2), 312-337.

54. Goyal RK, Shah VN, Saboo BD et al. (2010). Prevalence of Overweight and Obesity in India. Adolescent School Going Children: Its Relationship with Socioeconomic Status and Associated Lifestyle Factors. $J$ Assoc Physicians India, 58.

55. Manios Y, Kolotourou M, Moschonis G et al. (2005). Macronutrient intake, physical activity, serum lipids and increased body weight in primary schoolchildren in Istanbul. Pediatr Int, 47,159-166.

56. Darmon N, Drewmowski A. (2008). Does social class predict diet quality? Am J Clin Nutr, 87 (5), 1107-1117.

57. Ward PR, Verity F, Carter P et al. (2013). Food Stress in Adelaide: The Relationship between Low Income and the Affordability of Healthy Food. J Env Public Health, 10; 968078.

58. Frederick CB, Kaisa Snellman K, Putnam RD. (2014). Increasing socioeconomic disparities in adolescent obesity. Proceedings of the National Academy of Sciences of the United States of America 111(4); 1338-1342

59. Stang J, Story M. (2005). Guidelines for Adolescent Nutrition Services. Center for Leadership, Education, and Training in Maternal and Child Nutrition, Division of Epidemiology and Community Health, School of Public Health, University of Minnesota.

60. King KA, Mohl K, Bernard AL, Vidourek, RA. (2007). Does involvement in healthy eating among university students differ based on exercise status and reasons for exercise? Californian J Health Promot, 5(3), 106-119.

61. Gropper SQ, Smith JL, Groff JL. (2009). Advanced Nutrition and Human Metabolism. 5th Edition. Wadsworth, Cengage Learning.

62. Rosenheck R. (2008). Fast food consumption and increased caloric intake: a systematic review of a trajectory towards weight gain and obesity risk. The International Association for the Study of Obesity. Obes Rev, 9(6):53547.

63. French SA, Story M, Neumark-Sztainer D et al. (2001). Fast food restaurant use among adolescents: associations with nutrient intake, food choices and behavioral and psychosocial variables. Int J Obes, 25, 1823-33.

64. Ebbeling, C.B., Sinclair, K.B., Pereira, M.A., Gar-

African Health Sciences Vol 16 Issue 4, December, 2016 
cia-Lago, E., Feldman, H.A. Ludwig, D.A. (2004). Compensation for Energy Intake From Fast Food Among Overweight and Lean Adolescents. American Medical Association, 291(23), 2828-2833.

65. Amos, P.M., Intiful, F.D., Boateng, L. (2012). Factors That Were Found to Influence Ghanaian Adolescents' Eating Habits. Sage Open, 2, 1-6.

66. Salmon, J., Timperio, A., Telford, A., Carver, A., Crawford, D. (2005). Association of Family Environment with Children's Television Viewing and with Low Level of Physical Activity. Obesity Research, 13(11).

67. Campagnolo, P.D.B., Vitolo, M.R., Gama, C.M., Stein, A.T. (2008). Prevalence of overweight and associated factors in southern Brazilian adolescents. Public Health, 122, 509-515

68. Chou, S.Y. (2006). Fast-Food Restaurant Advertising on Television and Its Influence on Childhood Obesity. Lehigh University and National Bureau of Economic Research Inas Rashad, Georgia State University.

69. Utter, J., Neumark-Sztainer, D., Jeffery, R., Story, M. (2003). Couch potatoes or French fries: are sedentary behaviors associated with body mass index, physical activity, and dietary behaviors among adolescents? Journal of the American Dietetic Association online. 103(10):1298-305.

70. Matheson DM, Killen JD, Varady A (2004). Children's food consumption during television viewing. Am J Clin Nutr, 79, 6, 1088-1094.

71. Birch, L., Savage, J. S., \& Ventura, A. (2007). Influences on the Development of Children's Eating Behaviours: From Infancy to Adolescence. Canadian Journal of Dietetic Practice and Research: A Publication of Dietitians of Cana$\mathrm{da}=$ Revue Canadienne de La Pratique et de La Recherche En Dietetique : Une Publication Des Dietetistes Du Canada, 68(1), s1-s56.

72. Yannakoulia, M., Karayiannis, D., Terzidou, M., Kokkevi, A., Sidossis, L.S. (2004). Nutrition-related habits of Greek adolescents. European Journal of Clinical Nutrition, $58,580-586$

73. Dixona, H.G., Scullya, M.L., Wakefield, M.A., Whitea, V.M., Crawford, D.A. (2007). The effects of television advertisements for junk food versus nutritious food on children's food attitudes and preferences. Social Science \& Medicine, 65, 1311-1323.

74. Salvy, S.J., De La Haye, K., Bowker, J.C., Hermans, R.C.J. (2012). Influence of peers and friends on children's and adolescents' eating and activity behaviors. Physiology \& Behavior, 106, 369-378.
75. Parkes, A., Sweeting, H., Wight, D. (2012). Growing Up in Scotland: Overweight, obesity and activity, Edinburgh. Scottish Government

76. Brown, R., Odgen, J. (2004). Children's eating attitudes and behaviour: a study of the modelling and control theories of parental influence. Health Education Research, 19(3), 261-271.

77. Bargiota, A., Delizona, M., Tsitouras, A. and Koukoulis, G.N. (2013). Eating habits and factors affecting food choice of adolescents living in rural areas. Hormones, 12(2), 246-253.

78. S Savage, J. S., Fisher, J. O., \& Birch, L. L. (2007). Parental Influence on Eating Behavior: Conception to Adolescence. The Journal of Law, Medicine \& Ethics : A Journal of the American Society of Law, Medicine \& Ethics, 35(1), 22-34.

79. Wang, Y., Li, J., Caballero, B. (2009). Resemblance in Dietary Intakes between Urban Low-Income African-American Adolescents and Their Mothers: The Healthy Eating and Active Lifestyles from School to Home for Kids Study. Journal of American and Dietetic Association, 109, 52-63.

80. Scaglioni S, Arrizza C, Vecchi F (2011). Determinants of children's eating behaviour. Am J Clin Nutr, 94, 6.

81. Fortin, B., Yazbeck, M. (2011). Peer Effects, Fast Food Consumption and Adolescent Weight Gain. Centre Interuniversitaire sur le Risque, les politiques economiques et lemploi.

82. Wang, Z. (2004). Influences of Socioeconomic status, Dietary factors and physical activity on overweight, obesity of Australian children and adolescents. Thesis (PhD) Queensland University of Technology.

83. Atkin, D. (2013). The caloric costs of culture evidence from Indian Migrants. NBER Working Paper Series.

84. Johnston JL, Fanzo JC, Cogill B. (2014). Understanding Sustainable Diets: A Descriptive Analysis of the Determinants and Processes That Influence Diets and Their Impact on Health, Food Security, and Environmental Sustainability. Adv Nutr, 5, 418-429.

85. Perry, C.L., Maureen, T. Mcguire, Neumark-Sztainer, D., Story, M., (2001). Characteristics of vegetarian adolescents in a multi-ethnic urban population. Journal of Adolescent Health, 29(6), 406-16.

86. Prentice, A., Schoenmakers, I., Laskey, M. A., de Bono, S., Ginty, F., \& Goldberg, G. R. (2006). Symposium on "Nutrition and health in children and adolescents" Session 1: Nutrition in growth and development: Nutrition 
and bone growth and development. The Proceedings of the Nutrition Society, 65(4), 348-360.

87. Butte NF, Garza C, De Onis M. (2006). Evaluation of the feasibility of international growth standards for school-aged children and adolescents. Food and Nutrition Bulletin, vol. 27, no. 4 (supplement)

88. Perry CL, McGuire MT, Neumark-Sztainer D (2002). Adolescent Vegetarians How Well Do Their Dietary Patterns Meet the Healthy People 2010 Objectives? Arch Pediatr Adolesc Med; 156(5):431-437.

89. O'brien R., Perry, C.L, Wall, M.M, Story, M., Neumark-Sztainer, D., (2009). Adolescent and young adult vegetarianism: better dietary intake and weight outcomes but increased risk of disordered eating behaviors. Journal of the American Dietetic Association online, 109(4), 648-55.

90. World Health Organisation, (2005). Nutrition in adolescence - Issues and Challenges for the Health Sector. Issues in Adolescent Health and Development. Available at: http://apps.who.int/iris/bitstream/10665/43342/1/9241593660_eng.pdf

91. Amit, M. (2010). Vegetarian diets in children and adolescents. Paediatrics \& Child Health, 15(5), 303-308.

92. Richter M, Boeing H, Grunewald-Funk D et al (2016). or the German Nutrition Society (DGE) (2016) Vegan diet. Position of the German Nutrition Society (DGE). Ernahrungs Umschau 63(04): 92- 102. Erratum in: 63(05): M262

93. Lamisse, F., (2005). Vegetarianism in adolescents: risk or symptom? Objectif Nutrition online,75. Available from:http:/ /www.danoneinstitute.org/objective_nutrition_newsletter/on75.php

94. Sanders, T.A.B., Reddy, S., (1994). Vegetarian diets and children. American Journal of Clinical Nutrition, 59, 1176S-1181S

95. Donovan, U. M., Gibson, R.S., (1996). Dietary intakes of adolescent females consuming vegetarian, semi-vegetarian, and omnivorous diets. Journal of Adolescent Health online, 18(4), 292-300.

96. Lamisse, F. (2005). Vegetarianism in adolescents: risk or symptom? Objectif Nutrition, 75. Available from:

http://www.danoneinstitute.org/objective_nutrition_ newsletter/on75.php

97. Young, L.R. and Nestle, M. (2002). The contribution of expanding portion sizes to the US obesity epidemic. American Journal of PublicHealth, 92, 246-249.

98. Orlet Fisher, J.O., Rolls, B.J. and Birch, L.L. (2003). Children's bite size and intake of an entree are greater with large portions than with age-appropriate or self-selected portions. American Journal of Clinical Nutrition, 77(5), 1164-1170.

99. Ello-Martin, J.A., Ledikwe, J.H. and Rolls, B.J. (2005). The influence of food portion size and energy density on energy intake: implications for weight management. American Journal of Clinical Nutrition, 82, 236S-241S

100. Benton, D. (2015). Portion Size: What We Know and What We Need to Know. Critical Reviews in Food Science and Nutrition, 55(7), 988-1004. http://doi.org/10. 1080/10408398.2012.679980

101. Rolls, B.J., Morris, E.L. AND Roe, L.S. (2002). Portion size of food affects energy intake in normal-weight and overweight men and women. American Journal of Clinical Nutrition, 76, 1207-13.

102. Steenhuis, I.H.M. AND Vermeer, W.M. (2009). Portion size: review and framework for interventions. International Journal of Behavioral Nutrition and Physical Activity, $6(58)$.

103. Ebbeling, C.B., Sinclair, K.B., Pereira, M.A., Garcia-Lago, E., Feldman, H.A. AND Ludwig, D.A. (2004). Compensation for Energy Intake from Fast Food Among Overweight and Lean Adolescents. American Medical Association, 291(23), 2828-2833.

104. Crowe, T.C., La Fontaine, H., Gibbons, C.J., Cameron-Smith, D. AND Swinburn, B.A. (2004). Energy density of foods and beverages in the Australian food supply: influence of macronutrients and comparison to dietary intake. European Journal of Clinical Nutrition, 58, 1485-1491.

105. Astrup, A., Grunwald, G.K., Melanson, E.L., Saris, W.H., and Hill JO. (2000). The role of low-fat diets in body weight control: a meta-analysis of ad libitum dietary intervention studies. International Journal of Obesity and Related Metabolic Disorders, 24(12), 1545-1552

106. Alexy, U., Sichert-Hellert, W., M Kersting. AND Schultze-pawlitschko, V. (2004). Pattern of long-term fat intake and BMI during childhood and adolescence. Results of the DONALD Study. International Journal of Obesity 28: 1203-1209.

107. Vagstrand, K. (2008). Eating Habits among adolescents and their mothers. The Stockholm Weight Development Study (SWEDES) Karolinska Institutet

108. Chen, S. (2012). Association between dietary intake and nutritional status among adolescent girls in Kilosa District, Tanzania. Thesis. Anhui Medical University M.S., University of Massachusetts Amherst. 
109. Thomas, B., Bishop, J., Clayton, B.D. (2001). Manual of Dietetic Practice. 4thed. Blackwell Sciences Ltd by Blackwell Publishing Ltd.

110. Lee, S.K., Novotny, R., Daida, Y.G., Vijayadeva, V., Gittelsohn, J. (2007). Dietary Patterns of Adolescent Girls in Hawaii over a 2-Year Period. Journal of American and Dietetic Association, 107, 956-961.

111. Pearson, N., Atkin, A.J., Biddle, S.J.H., Gorely, S., Edwardson, C. (2009). Patterns of adolescent physical activity and dietary behaviours. International Journal of Behavioral Nutrition and Physical Activity, 6, 45.

112. Schusdziarra, V., Hausmann, M., Wittke, C., Mittermeier, J., Kellner, M., Naumann, A., Wagenpfeil, S., Erdmann, J. (2011). Impact of breakfast on daily energy intake - an analysis of absolute versus relative breakfast calories. Nutrition Journal, 10, 5.

113. Sjoberg, A., Hallberg, L., Ho"glund, D., Hulthe'n, L. (2003). Meal pattern, food choice, nutrient intake and lifestyle factors in The Go"teborg Adolescence Study European Journal of Clinical Nutrition, 57, 1569-1578
114. St-Onge, M.P., Keller, K.L., Heymsfield, S.T. (2003).

Changes in childhood food consumption patterns: a cause for concern in light of increasing body weights. American Journal of Clinical Nutrition, 78, 1068-1073.

115. Sebastian, R.S., Goldman, J.D. and Wilkinson, C. (2010). Snacking Patterns of U.S. Adolescents What We Eat In America, NHANES 2005-2006. Food Surveys Research Group Dietary Data Brief ,2.

116. Yoon, J.S., \& Lee, N.-J. (2010). Dietary patterns of obese high school girls: snack consumption and energy intake. Nutrition Research and Practice, 4(5), 433-437. http://doi.org/10.4162/nrp.2010.4.5.433 PubMed 117. Van der Horst, K., Oenema, A., Ferreira, I., Wendel-Vos, W., Giskes, K., Van Lenthe, F., Brug, J. (2006). A systematic review of environmental correlates of obesity-related dietary behaviors in youth. Health Educ. Res. 22 (2): 203-226.

118. Rennie, K.L., Johnson, L., Jebb, S, A. (2005) Behavioural determinants of obesity. Best Pract Res Clin Endocrinol Metab, 19:343-58 